\title{
Low Serum Cholesterol as a Risk Factor for Hemorrhagic Stroke in Men A Community-Based Mass Screening in Okinawa, Japan
}

\author{
Koichiro Okumura, MD; Kunitoshi Iseki, MD*; Kiyoshi Wakugami, MD; Yorio Kimura, MD; \\ Hiromi Muratani, MD; Yoshiharu Ikemiya, MD**; Koshiro Fukiyama, MD
}

\begin{abstract}
The relation between the level of total serum cholesterol and stroke is controversial. The relation between serum total cholesterol and subtypes of stroke was examined in the participants of a community-based mass screening program in Okinawa, Japan. A total of 38,053 subjects, whose serum level of cholesterol had been determined during a mass screening carried out in 1983, were examined to see whether they had experienced stroke during a 3-year period from 1988 to 1991. Of them, 315 subjects aged 33-93 years (174 men, 141 women) had had a stroke during that period. The types of stroke were cerebral infarction in 164 , cerebral hemorrhage in 111, subarachnoid hemorrhage in 19, and others in 21. In men, the odds ratio of cerebral hemorrhage was 0.71 (95\% confidence interval, 0.55-0.95), and the odds ratio of cerebral hemorrhage associated with serum level of cholesterol $\leq 167 \mathrm{mg} / \mathrm{dl}, 168-191 \mathrm{mg} / \mathrm{dl}, 192-217 \mathrm{mg} / \mathrm{dl}$, and $\geq 218 \mathrm{mg} / \mathrm{dl}$ were 1.00 (reference), 0.70 (0.38-1.30), 0.77 $(0.55-1.08), 0.73(0.56-0.96)$, respectively. Lower serum cholesterol was an independent predictor of cerebral hemorrhage in men. (Jpn Circ J 1999; 63: 53-58)
\end{abstract}

Key Words: Cerebral hemorrhage; Cerebral infarction; Serum cholesterol; Stroke

$\mathbf{H}$ percholesterolemia is a well-known risk factor of cardiovascular disease, in particular of coronary heart disease, and hypercholesterolemia is often found in association with other diseases such as renal disease with proteinuria, hypertension, and diabetes mellitus. Several studies have shown the beneficial effects of treating hypercholesterolemia in case of myocardial infarction? However, it is not clear whether treating hypercholesterolemia can help prevent stroke 3,4 Mortality due to stroke has dropped significantly in the past 30 years in Japan, despite the gradual increase in the serum level of cholesterol observed during the same period.

Data presented here are from the 1983 mass screening registry $(n=38,053)$ and the subsequent stroke registry of people living on the island of Okinawa, which is known for having the highest longevity rate ${ }^{6}$ and a low rate of death due to cardiovascular disease in Japan.

We examined the hypothesis that serum cholesterol was an independent predictor of stroke or stroke subtype in the general population.

\section{Methods}

Study Design

An epidemiological study was conducted concerning the

(Received June 16, 1998; revised manuscript received September 21, 1998; accepted September 22, 1998)

Third Department of Internal Medicine and $*$ Dialysis Unit, University of The Ryukyus, and **The Okinawa General Health Maintenance Association, Okinawa, Japan

Mailing address: Koichiro Okumura, MD, Third Department of Internal Medicine, University of The Ryukyus 207 Uehara, Nishihara-cho, Okinawa 903-0215, Japan risk factors of stroke in Okinawa, Japan, which had a population of 1.2 million according to a census carried out in 1990. All individuals over 18 years of age, who participated in the mass health screening carried out in 1983 and for whom data on serum cholesterol was available, were eligible for the study. Subjects were excluded from the study if data on birth date and serum cholesterol were not available in the computer data file. Independently, data from the Co-operative Study Group of Mortality and Morbidity due to Cardiovascular Diseases in Okinawa (COSMO) registry, which covered the same geographical area and filed all cases of stroke in the area, were available. The study period of the COSMO registry was 3 years, from April 1, 1988 to March 31, 1991. The cases of stroke found in the 1983 mass screening registry were identified using the 2 computer registries. Their identity was verified by name, sex, date of birth, zip code and, if necessary, by reviewing the medical codes. Cumulative incidence of stroke was calculated for each quartile of basal serum cholesterol and multiple logistic analysis was applied to examine the relationship between the occurrence of stroke and serum cholesterol levels.

\section{Mass Screening Registry}

A large community-based health examination program is carried out annually by the Okinawa General Health Maintenance Association (OGHMA) under the direction of Dr Ikemiya. The demographics of this registry have been published elsewhere ${ }^{7-9}$ In brief, the staff of the OGHMA, doctors and nurses, visit the people at their residence or at work, throughout the entire area of Okinawa once a year. They collect data on blood pressure as well as other parameters; then they inform each person of the results and, 
when necessary, recommend further examination. Blood pressure is measured using a standard mercury sphygmomanometer. Urinalysis is done using dip-sticks. Blood tests were optional until 1992 because the costs were not covered by the public insurance system. Fasting serum cholesterol is measured by the enzymatic oxydase method using a commercially available kit at the OGHMA laboratory! 10,11 Information regarding various lipoproteins, smoking, alcohol consumption, and drug use were not available in the computer file for 1983. The computerbased data file contained data for the fiscal year 1983; that is, from April 1, 1983 to March 31, 1984. A total of 107,192 residents over 18 years of age were entered in the 1983 mass screening registry, which was about $14.0 \%$ of the whole adult population.

Of them, we examined 38,053 subjects, 17,859 men and 20,194 women, for whom data on the level of serum cholesterol and other clinical variables were obtained at the time of the 1983 mass screening.

\section{Stroke Registry}

In a program independent of the 1983 mass screening, all cases of stroke that occurred in Okinawa between April 1, 1988 and March 31, 1991 were registered in the COSMO registry. Details of this registry have been published elsewhere!2 To attain this, we collaborated with the Okinawa Medical Association and visited 9 public hospitals, 25 main private hospitals and 7 public health centers. Because of the geographic location of Okinawa, after stroke the patients will seek medical treatment exclusively in Okinawa and the health insurance system covers almost all residents. The Department of Environment and Health of the Okinawa Prefectural Government and the Department of Legal Medicine of the University of the Ryukyus also cooperated with us in locating patients. Therefore, we think that this hospital-based registry covered virtually all cases of stroke that occurred in the prefecture. Criteria for the diagnosis of stroke were based on those used by the Ministry of Health and Welfare of Japan ${ }^{3-15}$ Diagnosis of stroke was categorized into 4 groups according to the subtype of stroke: cerebral infarction, cerebral hemorrhage, subarachnoid hemorrhage, and others. Others included patients with a stroke of undetermined type, with definite neurological deficit of acute onset suggesting stroke but for whom there was insufficient information to determine the stroke subtype. Medical records, including the history and laboratory data, were reviewed and registered.

\section{Statistical Analyses}

Paired t-test and equivalent non-parametric test and Wilcoxon rank-sum test were used to compare continuous variables. Fisher's exact test was used to compare differences among the groups of discrete variables. The cumulative incidence of stroke was calculated as the ratio of the number of strokes to the number of screened subjects at risk, being expressed per 100,000 subjects screened in 3 years. Serum cholesterol adjusted rates were calculated for age and other variables simultaneously using the Statistical Analysis System (SAS) package!6 The dependent variable in the model was binary; that is, Stroke or Non-Stroke during the study period. The odds ratio was calculated by the quartile of serum cholesterol with the co-variables in the computer registry? The co-variables were age (year old at the time of screening: $18-29,30-39,40-49,50-59$,
Table 1 Demographics of the Case-Stroke Patients Who Had Data of Serum Cholesterol at the 1987 Mass Screening

\begin{tabular}{lc}
\hline \hline No. cases (men/women) & $315(174 / 141)$ \\
Age at screening (years) & \\
Mean & 65.6 \\
SD & 11.4 \\
Range & $33 \sim 93$ \\
Serum cholesterol at screening $(\mathrm{mg} / \mathrm{dl})$ & \\
Mean & 196.9 \\
SD & 37.9 \\
Range & $111 \sim 352$ \\
Duration between screening and stroke (months) & \\
Mean & 72.6 \\
SD & 10.3 \\
Range & $52 \sim 94$ \\
\hline
\end{tabular}

Screening was performed from April 1983 to March 1984.

Table 2 Number of Cases of Stroke and Subtypes by the Quartile of Serum Cholesterol in the 1983 Mass Screening

\begin{tabular}{|c|c|c|c|c|}
\hline & \multicolumn{4}{|c|}{ Quartile serum cholesterol } \\
\hline & $1 s t$ & 2nd & $3 r d$ & 4 th \\
\hline \multicolumn{5}{|c|}{ Serum cholesterol $(\mathrm{mg} / \mathrm{dl})$} \\
\hline Range & $\leq 167$ & $168 \sim 191$ & $192 \sim 217$ & $218 \leq$ \\
\hline Mean & 149.3 & 179.8 & 203.7 & 245.3 \\
\hline$S D$ & 14.1 & 6.8 & 7.4 & 26.9 \\
\hline No. screenees & 9,498 & 9,737 & 9,531 & 9,287 \\
\hline Men $(\%)$ & $(49.0)$ & $(48.7)$ & $(47.8)$ & $(42.1)$ \\
\hline \multicolumn{5}{|c|}{ Age of screenees (years) } \\
\hline Mean & 46.9 & 51.5 & 53.9 & 56.3 \\
\hline$S D$ & 16.1 & 15.3 & 14.3 & 13.5 \\
\hline \multicolumn{5}{|l|}{ No. patients } \\
\hline \multicolumn{5}{|l|}{ Stroke } \\
\hline (m) & 50 & 47 & 46 & 31 \\
\hline$(w)$ & 18 & 29 & 50 & 44 \\
\hline \multicolumn{5}{|c|}{ Cerebral hemorrhage } \\
\hline$(m)$ & 23 & 18 & 14 & 8 \\
\hline$(w)$ & 6 & 12 & 20 & 10 \\
\hline \multicolumn{5}{|c|}{ Cerebral infarction } \\
\hline (m) & 22 & 26 & 28 & 19 \\
\hline$(w)$ & 8 & 13 & 21 & 27 \\
\hline \multicolumn{5}{|c|}{ Subarachnoid hemorrhage } \\
\hline$(m)$ & 2 & 1 & 2 & 1 \\
\hline$(w)$ & 2 & 2 & 6 & 3 \\
\hline \multicolumn{5}{|l|}{ Others } \\
\hline (m) & 3 & 2 & 2 & 3 \\
\hline$(w)$ & 2 & 2 & 3 & 4 \\
\hline
\end{tabular}

Screening was performed from April 1983 to March 1984. (m), men; (w), women.

60-69, 70+), systolic blood pressure ( $\mathrm{mmHg} \leq 119,120$ $129,130-139,140-149,150-159,160+)$, and proteinuria (normal (0), and abnormal (1)). The results of urinalysis were considered normal when the records indicated $(-)$ or $( \pm)$ for the dipstick urinalysis, and abnormal when the records indicated $(+)$ ? For all relative risk, we calculated $95 \%$ confidence limits. Data are expressed as the mean \pm SD.

\section{Results}

\section{Mass Screening Registry}

Serum levels of cholesterol distributed widely from 66 to $748 \mathrm{mg} / \mathrm{dl}$, median $180-189 \mathrm{mg} / \mathrm{dl}$. The screened subjects were grouped into quartiles according to the basal levels of serum cholesterol: $\leq 167 \mathrm{mg} / \mathrm{dl}(\mathrm{n}=9,498), 168-191 \mathrm{mg} / \mathrm{dl}$ $(\mathrm{n}=9,737), 192-217 \mathrm{mg} / \mathrm{dl}(\mathrm{n}=9,531)$, and $\geq 218 \mathrm{mg} / \mathrm{dl}(\mathrm{n}=$ $9,287)$. The mean levels of serum cholesterol in each quartile were $149.3 \mathrm{mg} / \mathrm{dl}, 179.8 \mathrm{mg} / \mathrm{dl}, 203.7 \mathrm{mg} / \mathrm{dl}$, and 245.3 
Table 3 Comparison of the Demographics at the Time of Screening Between the Case-Stroke and the Non-Case-Stroke Patients

\begin{tabular}{lccc}
\hline \hline & Case-stroke & Non-case-stroke & Total \\
\hline No. patients & 315 & 339 & 654 \\
(men, \%) & $(55.2)$ & $(53.1)$ & $(54.1)$ \\
Systolic blood pressure $(\mathrm{mmHg})$ & & & 147.2 \\
$\quad$ Mean & 153.9 & 140.9 & 21.1 \\
SD & 22.4 & 17.8 & 85.3 \\
Diastolic blood pressure (mmHg) & 88.6 & 82.2 & 11.8 \\
$\quad$ Mean & 12.0 & 10.7 & $583(91.5 \%)$ \\
SD & & $302(91.5 \%)$ & $54(8.5 \%)$ \\
Proteinuria & $281(91.5 \%)$ & $28(8.5 \%)$ & \\
$\quad$ Normal $(\%)$ & $26(8.5 \%)$ &
\end{tabular}

Normal proteinuria means (-) or (+) in the dipstick urinalysis, results $(+) \sim(+++)$ were abnormal.

Table 4 Results of Multiple Logistic Analysis on the Risk of Developing Stroke, Cerebral Hemorrhage, and Cerebral Infarction at the Time of the 1983 Mass Screening in Okinawa, Japan

\begin{tabular}{|c|c|c|c|}
\hline & \multicolumn{3}{|c|}{ Adjusted Odds ratio* ${ }^{*}(95 \%$ confidence interval) } \\
\hline & $\begin{array}{l}\text { Stroke } \\
(n=315)\end{array}$ & $\begin{array}{l}\text { Cerebral hemorrhage } \\
(n=111)\end{array}$ & $\begin{array}{c}\text { Cerebral infarction } \\
(n=164)\end{array}$ \\
\hline $\operatorname{Sex}($ men $=1$, women $=0)$ & $1.79(1.42 \sim 2.26)^{a}$ & $1.72(1.17 \sim 2.53)^{b}$ & $2.17(1.57 \sim 2.99)^{a}$ \\
\hline Age (years) & $1.80(1.62 \sim 2.20)^{a}$ & $1.61(1.36 \sim 1.91)^{a}$ & $2.01(1.72 \sim 2.34)^{a}$ \\
\hline Serum cholesterol $(\mathrm{mg} / \mathrm{dl})$ & $0.95(0.86 \sim 1.05)$ & $0.81(0.68 \sim 0.96)^{c}$ & $1.06(0.92 \sim 1.23)$ \\
\hline Systolic blood pressure ( $\mathrm{mmHg}$ ) & $1.32(1.23 \sim 1.43)^{a}$ & $1.35(1.19 \sim 1.53)^{a}$ & $1.34(1.21 \sim 1.49)^{a}$ \\
\hline Proteinuria & $0.92(0.64 \sim 1.32)$ & $1.22(0.70 \sim 2.10)$ & $0.74(0.44 \sim 1.27)$ \\
\hline
\end{tabular}

Odds ratio (95\% confidence interval) was calculated with variables in this table. Variables were categorized: age at screening: 18 29, 30 39, 40 49, 50 59, 60 69, 70+; serum cholesterol: $\leq 167,168 \sim 191,192 \sim 217,218 \leq$; systolic blood pressure: $\leq 119$, 120 129, 130 139, 140 149, 150 159, 160+; proteinuria was grouped into normal (0) and abnormal (1). Normal urinalysis denotes (-) or (+) of dipstick urinalysis, results $(+) \sim(++)$ were abnormal. Screening was performed from April 1983 to March 1984. ${ }^{a} p<0.0001,{ }^{b} p<0.01,{ }^{c} p<0.02$.

Table 5 Results of Multiple Logistic Analysis on the Risk of Developing Stroke, Cerebral Hemorrhage, and Cerebral Infarction in Both Sexes by the Serum Level of Cholesterol at the Time of the 1983 Mass Screening in Okinawa, Japan

\begin{tabular}{|c|c|c|c|}
\hline & \multirow{2}{*}{$n$} & \multicolumn{2}{|c|}{ Odds Ratio (95\% confidence interval) } \\
\hline & & Age-adjusted & Adjusted* $^{*}$ \\
\hline \multicolumn{4}{|l|}{ Men } \\
\hline Stroke & 174 & $0.97(0.71 \sim 1.33)$ & $0.89(0.77 \sim 1.02)$ \\
\hline Cerebral hemorrhage & 63 & $0.76(0.60 \sim 0.97)^{a}$ & $0.71(0.55 \sim 0.95)^{b}$ \\
\hline Cerebral Infarction & 95 & $1.08(0.89 \sim 1.30)$ & $1.02(0.84 \sim 1.23)$ \\
\hline \multicolumn{4}{|l|}{ Women } \\
\hline Stroke & 141 & $1.01(0.86 \sim 1.18)$ & $0.96(0.82 \sim 1.13)$ \\
\hline Cerebral hemorrhage & 48 & $1.12(0.89 \sim 1.42)$ & $0.87(0.66 \sim 1.14)$ \\
\hline Cerebral Infarction & 69 & $0.87(0.67 \sim 1.13)$ & $1.06(0.84 \sim 1.34)$ \\
\hline
\end{tabular}

Odds ratio (95\% confidence interval) was calculated with the quartiles of serum cholesterol. $*$ Adjusted for other variables listed in Table 4. ${ }^{a} p<0.0242,{ }^{b} p<0.005$.

$\mathrm{mg} / \mathrm{dl}$. The mean (SD) level of serum cholesterol was 191.9 (37.2) $\mathrm{mg} / \mathrm{dl}$ in men $(\mathrm{n}=17,859)$ and $196.1(39.2) \mathrm{mg} / \mathrm{dl}$ in women $(n=20,194)$. Other demographics such as blood pressure and urinalysis were previously reported elsewhere?-9

\section{Stroke Registry}

In all 4,756 cases of stroke were identified in 4,523 patients (2,463 men and 2,060 women) during the study period $!^{2}$ The number of first-ever stroke was 3,642 (80.5 $\%$ ): $79.6 \%$ in men and $81.4 \%$ in women. Computerized tomography was performed in $98.4 \%$ of the patients in this stroke registry. Of them, 654 patients (354 men and 300 women) were among the screenees. The annual number of strokes was 233 cases in 1988, 211 cases in 1989, and 210 cases in 1990. The number of case-stroke patients for whom data on serum cholesterol were available was 315 (174 men and 141 women) and that of non-case-stroke patients for whom data on serum cholesterol were not available was 339 (180 men and 159 women). The clinical demographics of the case-stroke are shown in Table 1.

\section{Serum Cholesterol as a Risk Factor of Stroke}

Table 2 shows the distribution of patients who suffered a stroke according to the level of serum cholesterol they had at the time of the mass screening. The 3-year cumulative incidences, per 100,000 subjects screened, of stroke, cerebral hemorrhage and cerebral infarction were calculated. The cumulative incidence of stroke was 1074, 991, 1010 and 793 for men, and 372, 581, 1005 and 818 for women for each respective quartile of serum cholesterol. In men, the cumulative incidence of cerebral hemorrhage was 494, 380,307 and 205 for each respective quartile of serum cholesterol. In women, the respective cumulative incidences were 123, 240, 402 and 186. The cumulative inci- 
Table 6 Results of Multiple Logistic Analysis on the Risk of Developing Stroke, Cerebral Hemorrhage, and Cerebral Infarction in Both Sexes Distributed According to their Serum Level of Cholesterol at the Time of the 1983 Mass Screening in Okinawa, Japan

\begin{tabular}{|c|c|c|c|c|c|}
\hline & \multicolumn{5}{|c|}{ Serum cholesterol } \\
\hline & $n$ & $\leq 167$ & $168 \sim 191$ & $192 \sim 217$ & $218 \leq$ \\
\hline \multicolumn{6}{|c|}{ Age-adjusted odds ratio (95\% confidence interval) } \\
\hline \multicolumn{6}{|l|}{ Men } \\
\hline Stroke & 174 & 1.00 & $0.89(0.59 \sim 1.33)$ & $0.99(0.81 \sim 1.21)$ & $0.93(0.80 \sim 1.08)$ \\
\hline Cerebral hemorrhage & 63 & 1.00 & $0.74(0.40 \sim 1.37)$ & $0.79(0.57 \sim 1.11)$ & $0.75(0.57 \sim 0.99)^{a}$ \\
\hline Cerebral Infarction & 95 & 1.00 & $1.13(0.64 \sim 2.01)$ & $1.19(0.90 \sim 1.58)$ & $1.05(0.85 \sim 1.29)$ \\
\hline \multicolumn{6}{|l|}{ Women } \\
\hline Stroke & 141 & 1.00 & $1.00(0.55 \sim 1.81)$ & $1.19(0.90 \sim 1.57)$ & $1.02(0.84 \sim 1.24)$ \\
\hline Cerebral hemorrhage & 48 & 1.00 & $1.18(0.44 \sim 3.17)$ & $1.27(0.80 \sim 2.02)$ & $0.86(0.61 \sim 1.21)$ \\
\hline Cerebral Infarction & 69 & 1.00 & $1.03(0.42 \sim 2.50)$ & $1.13(0.75 \sim 1.70)$ & $1.16(0.88 \sim 1.52)$ \\
\hline \multicolumn{6}{|c|}{ Adjusted odds ratio* $(95 \%$ confidence interval) } \\
\hline \multicolumn{6}{|c|}{  } \\
\hline Stroke & 174 & 1.00 & $0.88(0.57 \sim 1.29)$ & $0.97(0.79 \sim 1.19)$ & $0.91(0.78 \sim 1.06)$ \\
\hline Cerebral hemorrhage & 63 & 1.00 & $0.70(0.38 \sim 1.30)$ & $0.77(0.55 \sim 1.08)$ & $0.73(0.56 \sim 0.96)^{b}$ \\
\hline Cerebral Infarction & 95 & 1.00 & $1.11(0.62 \sim 1.96)$ & $1.17(0.88 \sim 1.55)$ & $1.03(0.84 \sim 1.28)$ \\
\hline \multicolumn{6}{|l|}{ Women } \\
\hline Stroke & 141 & 1.00 & $0.96(0.53 \sim 1.75)$ & $1.15(0.88 \sim 1.52)$ & $0.98(0.81 \sim 1.19)$ \\
\hline Cerebral hemorrhage & 48 & 1.00 & $1.16(0.43 \sim 3.13)$ & $1.26(0.79 \sim 1.99)$ & $0.84(0.70 \sim 1.19)$ \\
\hline Cerebral Infarction & 69 & 1.00 & $0.97(0.40 \sim 2.35)$ & $1.08(0.72 \sim 1.64)$ & $1.11(0.85 \sim 1.46)$ \\
\hline
\end{tabular}

Odds ratio (95\% confidence interval) was calculated with reference to the lowest quartile of serum cholesterol. *Adjusted for other variables listed in Table 4 . ${ }^{a} p<0.0386,{ }^{b} p<0.0232$.

dence of cerebral infarction was $473,548,615$ and 486 , respectively, in men and 165, 260, 422 and 502, respectively, in women.

Table 3 summarizes the demographics of stroke patients. In the case-stroke group, the percentage of men and the occurrence of proteinuria were the same as those in the non-case-stroke group; however, both systolic and diastolic blood pressure were slightly higher in the former group than in the latter $(\mathrm{p}<0.0001)$.

The relative strength of the variables as risk factors of stroke, cerebral hemorrhage and cerebral infarction was tested by multiple logistic analysis. Male sex and age were strong predictors of stroke, cerebral hemorrhage and cerebral infarction (Table4). Apart from non-treatable variables and hypertension, low levels of serum cholesterol remained a significant risk factor for developing cerebral hemorrhage. The odds ratio (95\% confidence interval) of serum cholesterol was $0.81(0.68-0.96)(\mathrm{p}<0.02)$. The risk of cerebral hemorrhage was low, about $25 \%$ between the lowest and the highest quartile of serum cholesterol. This was quite obvious in men. Table 5 shows the results of multiple logistic analysis in each sex. In both men and women, the adjusted odds ratio of cerebral hemorrhage was less than 1.00 and that of cerebral infarction was larger than 1.00. Especially in men, both age-adjusted and adjusted odds ratio of cerebral hemorrhage was less than 1.00. Table 6 shows the association between the risk of stroke and the level of serum cholesterol calculated by reference to the lowest quartile of serum cholesterol. The odds ratio of cerebral hemorrhage in men was less than 1.00 , in particular the age-adjusted odds ratio of the highest quartile was $0.75(0.57-0.99)$, and the adjusted odds ratio was $0.73(0.56-0.96)$.

\section{Discussion}

The annual incidence of stroke in Okinawa, Japan was 137 per 100,000 subjects in the total population and 315 in the population aged 40 years and older. The cumulative incidence was 203 for the whole group screened in 1983 and 276 for those for whom data on serum cholesterol were obtained at that time. The crude annual incidence rate of stroke was 261 per 100,000 standard population of Japan in residents aged 20 years and older in Shibata (1976-78), Japan ${ }^{17}$ The population screened in Okinawa accounted for $14.0 \%$ of the total adult population of the prefecture. Because stroke occurred mostly in the adult population, the expected number of strokes can be calculated as the total number of registered cases of stroke $(n=4,523)$ multiplied by 0.140 (ie, 633) and the actually observed number of cases was 654 . Therefore, the sample size and distribution of sex and age in this screening registry were considered adequate and representative of the whole adult population.

The mean serum cholesterol levels in Okinawa were not significantly different compared with national populationbased samples screened in 1980; in fact, they were rather slightly higher on average.

\section{Study Limitations}

Several limitations in this study should be addressed. First, we did not investigate the stroke cases that occurred (or might have occurred) in the 4 years just after the screening; that is, from April 1984 to March 1988. However, the MRFIT study reported that the relation of the serum cholesterol level to death from intracranial hemorrhage was inverse, and this relation did not change when deaths during the first 3 years of follow-up and those during the last 3 years were examined ${ }^{18}$ So this factor would have a negligible effect in the determination of the relationship between serum cholesterol and stroke if the risk factors of stroke had exposed constantly, at least from 1983 to 1991. Actually, a significant positive correlation between serum cholesterol and acute myocardial infarction was observed in this registry! ${ }^{10}$ There were no specific changes in lifestyle or dietary habits during the study period. However, treatment strategies had slightly changed because of the introduction of HMG-CoA reductase inhibitors in August 1989 and several new antihypertensive drugs. The mean level of serum cholesterol was slightly lower at 190.9 $\mathrm{mg} / \mathrm{dl}$, than that measured at the time of screening (ie, $196.9 \mathrm{mg} / \mathrm{dl}$ ) (Table 1). Some studies have reported that HMG-CoA reductase inhibitors contributed to the reduc- 
tion in the occurrence of stroke ${ }^{19,20}$ Second, the stroke registry used in this study was basically a hospital-based registry; therefore, one might argue that several other cases may have been missed because of non-compliance or unknown reasons. We obtained the collaboration of the Okinawa Medical Association and other main hospitals in Okinawa. The number of strokes in the present study might be a little lower than the actual number of strokes, but these medical facilities covered more than $95 \%$ of the cases of systemic lupus erythematosus in the same entire area of Okinawa, ${ }^{21}$ and in the COSMO study, 63 death certificates relating to stroke were identified in the designated city and 61 of them $(96.8 \%)$ had also been registered. ${ }^{2}$ Moreover, the incidence of stroke reported in this study is not lower than that of other reports from Japan, ${ }^{20,22}$ so we think this possibility is negligible. Third, whether the association between serum cholesterol and incidence of stroke was due to the initiation of stroke or to the progression of pre-existing sclerotic process was not clear in this study. In this regard, mass trials to assess the effects of treatment for hypercholesterolemia on the incidence of stroke are necessary. The influence of severe hypercholesterolemia is relatively small in Japan compared with Europe and the USA. Therefore, the contribution of extremely high serum cholesterol to the risk of developing a stroke was uncertain in this study. Similarly, it was previously reported that there was no relation between serum cholesterol and cerebral infarction 23 The subjects who underwent blood tests (case-stroke) had higher blood pressure than those who were not subjected to blood tests (non-case-stroke) (Table 3). It is possible that screenees with high serum cholesterol may have a better opportunity to enhance medical compliance. Finally, information regarding other risk factors such as glycosemia, smoking, alcohol intake, lipids fractions, family history, past history, and drug use was not available. The effect of other possible predictors of stroke such as obesity and fat distribution deserve further investigation.

The reason why low serum cholesterol was associated with an increased occurrence of cerebral hemorrhage, especially in men, is not clear. Both an animal study ${ }^{24}$ and epidemiological studies ${ }^{18,25-27}$ have shown an inverse relation between serum cholesterol and cerebral hemorrhage exclusively in men. The Framingham Study has shown that the serum level of all persons over the age of 65 was inversely related to the incidence of stroke generally and to atherothrombotic brain infarction specifically.28 Other studies have shown no correlation29,30 Animal studies have shown that plasmatic arterionecrosis, the causative lesion of hypertensive cerebral hemorrhage, follows upon medial muscle cell necrosis. The earliest cerebral arterial change seen in hypertensive rats was inhibited when these animals were fed a cholesterol and lard-supplemented diet ${ }^{31}$ Other previous studies suggested that the membrane characteristics in stroke-prone spontaneously hypertensive rats depended partially on the amount of cholesterol in which was significantly decreased in stroke-prone spontaneously hypertensive rats and the erythrocytes from the group with a family history of stroke were more labile than those with no family history of stroke $3^{2}$ Low serum cholesterol may suggest the existence of malnutrition and is often found associated with a low level of plasma albumin. Low plasma levels of albumin have been shown to be associated with an increased risk of stroke 33,34 A very high incidence of cerebral hemorrhage was observed in a population on chronic dialysis where malnutrition is prevalent 35 Based on the dramatic decrease in deaths due to stroke in Japan, we speculate a dietary and/or nutritional improvement may have played a role, at least partly, through an increase in serum cholesterol contributing to the longevity of Japanese ${ }^{36,37}$ However, based on the results of the multiple logistic analysis, the effect of hypertension on the occurrence of stroke (Table 4) was much stronger than any other variables 38 In the present study, low serum cholesterol was not significantly associated with an increased occurrence of cerebral hemorrhage in women. The adjusted odds ratio for cerebral hemorrhage in women was larger than 1.00 except for the highest quartile of cholesterol level, and the odds ratio of the highest quartile was not significant. Other factors that we did not examine in the present study might affect the occurrence of cerebral hemorrhage. A previous study has shown that high alcohol intake was a statistically significant risk factor for cerebral hemorrhage in women, and current smoking was associated with cerebral hemorrhage in women but not in men 39 Further examinations are necessary.

In conclusion, the present study demonstrated that low serum cholesterol is an independent predictor of cerebral hemorrhage in men of Okinawa, Japan. The risk of cerebral hemorrhage decreased with higher serum cholesterol levels. Medical advice for further work-up is necessary for the screenees with low serum cholesterol, especially in men. The public health impact of what should be evaluated after examining other morbid conditions associated with serum cholesterol. ${ }^{10,11,40}$

\section{Acknowledgments}

This study was supported in part by grants from the Ministry of Health and Welfare of Japan to Dr K. Iseki and Dr K. Fukiyama.

We are indebted to the staff of COSMO group and to the staff of OGHMA, in particular to Mr M. Itokazu, for retrieving the data file from the 1983 mass screening. Physicians and medical facilities belonging to the COSMO group are listed in reference 12. We are grateful to Dr O. Morita, Department of Physics, Kyushu University, Fukuoka, Japan, for preparing the computer program used to identify stroke, and for other technical suggestions. Registration and data processing were done by Mrs C. Iseki.

\section{References}

1. Kannel WB, Castelli WP, Gordon T: Cholesterol in the prediction of atherosclerosis disease: New prospect based on the Framingham study. Ann Intern Med 1979; 90: $85-91$

2. Tyroler HA: Review of lipid-lowering clinical tries in relation to observational epidemiologic studies. Circulation 1987; 76: 515-522

3. Dyker AG, Weir CJ, Lees KR: Influence of cholesterol on survival after stroke: retrospective study. BMJ 1997; 314: 1584-1588

4. Hebert PR, Gaziano JM, Hennekens CH: An overview of trials of cholesterol lowering and risk of stroke. Arch Intern Med 1995; 155: $50-55$

5. Statistical and Information Department, Minister's Secretarial, Ministry of Health and Welfare: Health and welfare statistics in Japan. Tokyo: Health and Welfare Statistics Association, 1993

6. Health and Welfare Statistics Association: Health service in Japan: Incidence of health and welfare. Japan: 1992; 39: (in Japanese)

7. Iseki K, Iseki C, Ikemiya Y, Fukiyama K: Risk of developing endstage renal disease in a cohort of mass screening. Kidney Int 1996; 49: $800-805$

8. Iseki K, Ikemiya Y, Fukiyama K: Blood pressure and risk of endstage renal disease in a screened cohort. Kidney Int 1996; (Suppl 55): S69-S71

9. Iseki K, Ikemiya Y, Fukiyama K: Risk factors of end-stage renal disease and serum creatinine in a community-based mass screening. Kidney Int 1997; 51: 850-854

10. Wakugami K, Iseki K, Kimura Y, Okumura K, Ikemiya Y, Muratani $\mathrm{H}$, et al: Relationship between serum cholesterol and the risk of acute myocardial infarction in a screened cohort in Okinawa, Japan. Jpn Circ J 1998; 62: 7-14 
11. Iseki K, Ikemiya Y, Fukiyama K: Serum cholesterol and risk of endstage renal disease in cohort of mass screening. Clin Exp Nephrol 1998 (in press)

12. Kinjo K, Kimura Y, Shinzato Y Tomori M, Komine Y, Kawazoe N, et al, and COSMO Group: An epidemiological analysis of cardiovascular disease in Okinawa Japan. Hypertens Res 1992; 15: 111-119

13. Hatano S: Experience from a multicenter stroke register: a preliminary report. Bull WHO 1976; 54: 541-553

14. 63A-1 Study Group on the Registration/ Management/ Follow-up System of Circulatory Disease Patients: The guidelines for registration/ follow-up of cerebrovascular disease patients. 1988 (in Japanese)

15. Tazaki Y: Topics of cerebrovascular disturbance. Medicina 1984; 21: 1897-1899 (in Japanese)

16. SAS/STAT: User's guide, Release 6.03 Edition. Cary, NC: SAS Institute Inc, 1988

17. Tanaka H, Ueda Y, Date C, Baba T, Yamashita H, Hayashi M, et al: Incidence of stroke in Shibata, Japan, 1976-1978. Stroke 1981; 12: $460-466$

18. Iso H, Jacobs DR Jr, Wentworth D, Neaton JD, Cohen JD, for the MRFIT Research Group: Serum cholesterol levels and six-year mortality from stroke in 350,977 men screened for The Multiple Risk Factor Intervention Trial. N Engl J Med 1989; 320: 904-910

19. Blauw GJ, Lagaay AM, Smelt AH, Westendorp RG: Stroke, statins, and cholesterol: A meta-analysis of randomized, placebo-controlled, double-blind trials with HMG-CoA reductase inhibitors. Stroke 1997; 28: 946-950

20. Crouse JR III, Byington RP, Hoen HM, Furberg CD: Reductase inhibitor monotherapy and stroke prevention. Arch Intern Med 1997; 157: $1305-1310$

21. Iseki K, Miyasato F, Oura T, Uehara H, Nishime K, Fukiyama K: An epidemiologic analysis of end-stage lupus nephritis. Am J Kidney Dis 1994; 23: $547-554$

22. Shimamoto T, Komachi Y, Inada H, Doi M, Iso H, Sato S, et al: Trends for coronary heart disease and stroke and their risk factors in Japan. Circulation 1989; 79: 503-515

23. Szatrowski TP, Peterson AV Jr, Shimizu Y, Prentice RL, Mason MW, Fukunaga Y, et al: Serum cholesterol, other risk factors, and cardiovascular disease in a Japanese cohort. J Chronic Dis 1984; 37: $569-584$

24. Yamori Y, Horie R, Ikeda K, Nara Y, Lovenberg W: Prophylactic effect of dietary protein on stroke and its mechanism. In: Yamori Y, Lovenberg W, Reis ED, editors. Prophylactic approach to hypertensive disease. New York: Raven Press 1979: 497-504

25. Tanaka H, Ueda Y, Hayashi M, Date C, Baba T, Yamashita H, et al: Risk factors for cerebral hemorrhage and cerebral infarction in a Japanese rural community. Stroke 1982; 13: $62-73$

26. Konishi M, Iso H, Komachi Y, Iida M, Shimamoto T, Jacobs DR, et al: Associations of serum total cholesterol, different types of stroke, and stenosis distribution of cerebral arteries: The Akita Pathology Study. Stroke 1993; 24: 954-964

27. Ueshima H, Iida M, Shimamoto T, Konishi M, Tsujioka K, Tanigaki $\mathrm{M}$, et al: Multivariate analysis of risk factors for stroke: Eight-year follow-up study of farming villages in Akita, Japan. Prev Med 1980; 9: $722-740$

28. Wolf PA, Kannel WB, Verter J: Current status of risk factors for stroke. Neurol Clin 1983; 1: 317-343

29. Prospective Studies Collaboration: Cholesterol, diastolic blood pressure, and stroke: 13,000 strokes in 450,000 people in 45 prospective cohorts. Lancet 1995; 346: $1647-1653$

30. Tell GS, Crouse JR, Furberg CD: Relation between blood lipids, lipoproteins and cerebrovascular atherosclerosis: A review. Stroke 1988; 19: $423-430$

31. Ooneda G, Yoshida Y, Shinkai H, Hori S, Kobori K, Takayama Y, et al: Smooth muscle cells in the development of plasmitic arterionecrosis, arteriosclerosis, and arterial contraction. Blood Vessels 1978; 15: $148-156$

32. Yamori Y, Nara Y, Horie R, Ooshima A: Abnormal membrane characteristics of erythrocytes in rat models and men with predisposition to stroke. Clin Exp Hypertens 1980; 6: 1009-1021

33. Kimura N, Nakayama Y, Tashiro H: The 15 year follow-up population survey on cerebrovascular disease in rural Kyushu, Japan. Jpn J Med 1977; 16: $142-144$

34. Kimura N, Toshima H, Nakayama Y, Takayama K, Tashiro H, Takagi M: Fifteen-year follow-up population survey on stroke: multivariate analysis of the risk of stroke in farmers of Tanushimaru and fisherman of Ushibuka. In: Katz AAM, editor. Perspectives in cardiovascular research, Vol. 4. Yamori Y, Lovenberg W, Frei ED, editors. Prophylactic approach to hypertensive disease. New York: Raven Press, 1979; 505-510

35. Iseki K, Kinjo K, Kimura Y, Osawa A, Fukiyama K: Evidence for high risk of cerebral hemorrhage in chronic dialysis patients. Kidney Int 1993; 44: 1086-1090

36. Marmot MG, Smith GD: Why are the Japanese living longer? BMJ 1989; 299: $1547-1551$

37. Blackburn H, Jacobs DR Jr: The ongoing natural experiment of cardiovascular disease in Japan. Circulation 1989; 79: 718-720

38. Omae T, Ueda K: Hypertension and cardiovascular disease: the Japanese experience (Editorial Review). J Hypertens 1988; 6: $343-$ 349

39. Iribarren C, Jacobs DR, Sadler M, Claxton AJ, Sidney S: Low total serum cholesterol and intracerebral hemorrhagic stroke: is the association confined to elderly men? The Kaiser Permanente Medical Care Program. Stroke 1996; 27: 1993-1998

40. Iso H, Naito Y, Kitamura A, Sato S, Kiyama M, Takayama Y, et al: Serum total cholesterol and mortality in a Japanese population. $J$ Clin Epidemiol 1994; 47: 961-969 